\title{
Protein S deficiency and novel oral anticoagulants: an intriguing case
}

Dolors Tàssies (1) and Pablo García de Frutos (2)

1 Department of Hemotherapy and Hemostasis, Hospital Clinic, Institut d'Investigacions Biomèdiques August $\mathrm{Pi}$ i Sunyer (IDIBAPS), University of Barcelona, Barcelona, Catalonia, Spain.

2 Institute of Biomedical Research of Barcelona, IIBB-CSIC, IDIBAPS, Barcelona, Spain.

Vitamin $\mathrm{K}$ - dependent protein $\mathrm{S}$ (ProS) is a plasma glycoprotein with anticoagulant properties [1]. Its anticoagulant function is well established in the literature based both in clinical data, genetics and laboratory assays. ProS is able to prolong the clotting time acting as cofactor for activated protein C. Furthermore, since the $80 \mathrm{~s}$ it is known that hereditary ProS deficiency (PSD) increases the risk of venous thrombosis in families with hereditary thrombophilia [2], later found to be mostly caused by mutations in its coding gene, PROS1. Indeed, mutations in PROS1 have been shown to confer more than 7-fold risk of thrombosis in selected families with PSD [3]. The recent establishment of mice strains with mutations in Pros 1 has emphasized the importance of ProS as a pleiotropic anticoagulant in vivo $[4,5]$.

Nevertheless, although the view of ProS as an essential natural anticoagulant is wellgrounded, we could consider that ProS is one of the components of the coagulation cascade that has brought more surprising discoveries in recent years. The seminal work by Dahlbäck demonstrating that ProS interacted with high affinity with the complement regulator $\mathrm{C} 4 \mathrm{~b}$-binding protein (C4BP) and that a high molecular weight 1:1 ProS-C4BP complex was present in human plasma [6], was an early basis for the concept of hemostasis and inflammation as parts of a global response to damage, which has led to the present concept of thrombo-inflammation [7]. The C4BP-ProS complex has implications in PSD, which has been classified in three categories: type I corresponding to concentrations of total ProS antigen below the normal range (quantitative deficiency), type II being normal levels of a ProS with low activity (qualitative deficiency) and type III corresponding to a specific quantitative deficiency of free, uncomplexed ProS in plasma despite levels of total ProS antigen inside the normal range $[1,8]$.

More recently, the discovery of ProS and GAS6 as ligands of receptor tyrosine kinases and the discovery of its growth-factor like properties have brought new functional horizons to ProS, including its important implication in apoptotic cell removal (efferocytosis) and "taming" of inflammatory reactions [4, 8, 9]. Its role as anticoagulant has also been revised by the suggestion of new mechanisms, including the binding and effect of $\mathrm{Zn}^{2+}$ ions [11] and the ProS-dependent inhibition of factor Xa by TFPI [12]. From this studies, an antithrombotic activity of ProS that is independent of the action on activated protein $\mathrm{C}$ has been proposed and corroborated by in vivo studies in mice [4] and primates [13].

The study of the molecular basis of PSD has also provided some surprises. Studies of thrombophilia in different geographical areas have found that the incidence and type of PSD is very heterogeneous among populations [14]. In families with hereditary PSD 
where the traditional sequence technology failed to find a causative mutation, the use of new genetic screening techniques have discovered a relatively high frequency of small and large deletions in or close to the PROS1 locus [15,16]. Finally, relatively mild polymorphism in PROS1 could manifest as causative mutations in combination with other thrombophilic factors, especially in combination with the FV Leiden mutation, suggesting that there could be possible mechanisms of prothrombotic synergy among common genetic variants $[17,18]$.

In this context, the study by Wypasek et al. presents an interesting observation. The authors describe two families with severe familiar PSD due to a non-sense mutation and an insertion leading to a frame shift mutation. Both mutations predict truncated protein products. In both probands, plasma free ProS levels are very low, below $20 \%$ although in one case the total ProS level was inside the reference range, and should be considered a type III deficiency.

Both cases were treated with the new oral anticoagulant rivaroxaban, a selective direct factor Xa inhibitor. Interestingly, in both patients, thrombotic complications occurred under rivaroxaban therapy at two and five months of treatment respectively, and in consequence the antithrombotic therapy had to be modified. This observation could suggest that rivaroxaban is less effective for the treatment of thrombosis in patients with severe PSD. Nevertheless, the authors state that in their clinical experience with mild PSD patients (ie above $30 \%$ free ProS level) or in cases of protein $\mathrm{C}$ deficiency, the clinical response to rivaroxaban was similar to that observed in patients without thrombophilia.

At present, there are no large studies on the efficacy of each novel oral anticoagulant depending on specific causes of thrombophilia. Still, it is important to have in mind that the new oral anticoagulants interact with one specific target in the coagulation cascade (factor Xa for rivaroxaban), as opposed to the anti-vitamin $\mathrm{K}$ oral anticoagulants or heparins that interact with several coagulation factors. In principle, different genetic causes of thrombophilia could affect differently the effect of these drugs.

In the cases reported by Wypasek et al., one could speculate that the very low ProS concentration eliminates the natural inhibitory mechanism controlling factor Xa through TFPI. This could be aggravated by the fact that PSD patients show also decreased plasma concentration of TFPI [18]. Overall, these could result in less control of the factor $\mathrm{Xa}$ activity generated in severe PSD patients compared to patients with a different protrombotic origin.

Although it could now seem far-fetched, the combined knowledge on the specific causes of thrombophilia, their mechanisms of action, and how these mechanisms interact with different antithrombotic drugs could lead to personalized treatments that would be more efficient.

[1] García de Frutos P, Fuentes-Prior P, Hurtado B, Sala N. Molecular basis of protein S deficiency. Thromb Haemost 2007;98:543-56. 
[2] Comp PC, Nixon RR, Cooper MR, Esmon CT. Familial Protein S Deficiency is Associated with Recurrent Thrombosis. J Clin Invest 1984;74:2082-8.

[3] Simmonds RE, Ireland H, Lane DA, Zoller B, García de Frutos P, Dahlback B, et al. Clarification of the risk for venous thrombosis associated with hereditary protein $S$ deficiency by investigation of a large kindred with a characterized gene defect. Ann Intern Med 1998;128:8-14.

[4] Burstyn-cohen T, Heeb MJ, Lemke G. Lack of Protein S in mice causes embryonic lethal coagulopathy and vascular dysgenesis. J Clin Invest 2009.

[5] Saller F, Brisset AC, Tchaikovski SN, Azevedo M, Chrast R, Fernández J a, et al. Generation and phenotypic analysis of protein S-deficient mice. Blood 2009;114:2307-14.

[6] Dahlbäck B, Stenflo J. High molecular weight complex in human plasma between vitamin K-dependent protein $\mathrm{S}$ and complement component $\mathrm{C} 4 \mathrm{~b}$ binding protein. Proc Natl Acad Sci U S A 1981;78:2512-6.

[7] Esmon CT. Molecular circuits in thrombosis and inflammation. Thromb Haemost 2013;109:416-20.

[8] Castoldi E, Maurissen LFA, Tormene D, Spiezia L, Gavasso S, Radu C, et al. Similar hypercoagulable state and thrombosis risk in type I and type III protein Sdeficient individuals from mixed type I / III families. Haematologica 2010;95:1563-71.

[9] Middleton J. Innate immunity: TAMing inflammation. Nat Rev Immunol 2008;8:93-93.

[10] Anderson HA, Maylock CA, Williams JA, Paweletz CP, Shu H, Shacter E. Serum-derived protein $S$ binds to phosphatidylserine and stimulates the phagocytosis of apoptotic cells. Nat Immunol 2003;4:87-91.

[11] Fernandes N, Mosnier LO, Tonnu L, Heeb MJ. $\mathrm{Zn}^{2}(+)$-containing protein S inhibits extrinsic factor $\mathrm{X}$-activating complex independently of tissue factor pathway inhibitor. J Thromb Haemost 2010;8:1976-85.

[12] Peraramelli S, Rosing J, Hackeng TM. TFPI-dependent activities of protein S. Thromb Res 2012;129 Suppl :S23-6.

[13] Heeb MJ, Marzec U, Gruber a, Hanson SR. Antithrombotic activity of protein S infused without activated protein $\mathrm{C}$ in a baboon thrombosis model. Thromb Haemost 2012;107:690-8.

[14] Tang L, Jian X-R, Hamasaki N, Guo T, Wang H-F, Lu X, et al. Molecular basis of protein S deficiency in China. Am J Hematol 2013;88:899-905.

[15] Lind-Halldén C, Dahlen A, Hillarp A, Zöller B, Dahlbäck B, Halldén C. Small and large PROS1 deletions but no other types of rearrangements detected in patients with protein S deficiency. Thromb Haemost 2012;108:94-100. 
[16] Pintao MC, Garcia a a, Borgel D, Alhenc-Gelas M, Spek C a, de Visser MCH, et al. Gross deletions/duplications in PROS1 are relatively common in point mutation-negative hereditary protein S deficiency. Hum Genet 2009;126:449-56.

[17] Giri TK, Yamazaki T, Sala N, Dahlbäck B, de Frutos PG. Deficient APC-cofactor activity of protein $S$ Heerlen in degradation of factor Va Leiden: a possible mechanism of synergism between thrombophilic risk factors. Blood 2000;96:523-31.

[18] Segers O, Simioni P, Tormene D, Castoldi E. Influence of single nucleotide polymorphisms on thrombin generation in factor $\mathrm{V}$ Leiden heterozygotes. Thromb Haemost 2013;111:1-9. 